\title{
The GEOSS Science and Technology Service Suite: Linking S\&T Communities and GEOSS
}

\author{
H. -P. Plag ${ }^{1}$, I. McCallum ${ }^{2}$, S. Fritz ${ }^{2}$, S. Jules-Plag ${ }^{3}$, M. Nyenhuis ${ }^{4}$, S. Nativi ${ }^{5}$ \\ ${ }^{1}$ University of Nevada, Reno, Nevada Bureau of Mines and Geology, Reno, NV, USA, hpplag@unr.edu \\ 2 International Institute for Applied Systems Analysis, ESM Program, Austria, mccallum@iiasa.ac.at \\ ${ }^{3}$ Tiwah, Inc., Reno, NV, USA, julesplag@tiwah.com \\ ${ }^{4}$ University of Bonn, Department of Geography, Bonn, Germany, michael.nyenhuis@uni-bonn.de \\ ${ }^{5}$ National Research Council - Institute of Atmospheric Pollution Research, Italy stefano.nativi@cnr.it
}

\begin{abstract}
The Global Earth Observation System of Systems (GEOSS) is implemented by the Group on Earth Observations (GEO) with the goal to ensure that decision in nine Societal Benefit Areas (SBAs) of Earth observations (EOs) can be informed by sustained Earth observations. Extracting actionable information from Earth observations often depends on research, and utilization of the societal benefits of EOs requires the involvement of science and research communities. Building a GEOSS responding to the needs of a wide range of users necessitates contributions from many science and technology (S\&T) communities. The success of GEOSS depends on a outreach of GEO to the relevant S\&T communities, and the outreach concept has a focus on demonstrated services for S\&T communities. The GEO Work Plan includes several Tasks focusing on outreach to S\&T communities, and most of the GEO Community of Practice have a strong S\&T component. Infrastructure serving and linking S\&T users communities and GEOSS has been developed and is integrated into a GEOSS S\&T Service Suite. The GEOSS S\&T Stakeholder Network facilitates input from S\&T communities to GEO.
\end{abstract}

Key words: Earth observations, Observing systems, Societal Benefits, Stakeholder network, Science and Technology Communities

\section{Introduction}

The Global Earth Observation System of Systems (GEOSS) developed by the Group on Earth Observations (GEO) aims to provide comprehensible Earth observations (EOs) in support of decision making in a wide range of societal benefit areas. The nine interdependent Societal Benefit Areas (SBAs) addressed by GEO require an interdisciplinary scientific approach, and scientific interpretation of the EOs provided by GEOSS is necessary in order to derive actionable information. A strong engagement of science and technology (S\&T) communities in both the development and use of GEOSS is necessary to address the complex issues of the global integrated Earth system; improve interoperability between global observing, modeling, and information systems; facilitate data sharing, archiving, dissemination, and reanalysis; optimize the recording of observations, assimilation of data into models, and generation of data products; enhance the value of observations from individual observing systems through their integration in the SBAs; and harmonize wellcalibrated, highly accurate, stable, sustained in-situ and satellite observations of the same variable recorded by different sensors and different agencies.

Many of the Participating Organizations in GEO have a focus on S\&T. Most of the GEO Communities of Practice (CoPs) also have a strong S\&T component. Nevertheless, there are still many relevant S\&T communities that are not sufficiently linked to GEO and GEOSS.

The S\&T Road Map of GEO (GEO STC, 2010) defines a number of outreach activities in order to ensure a broad S\&T support for GEOSS and a wide use of GEOSS products by S\&T communities. The GEO Work Plan includes several Tasks focusing on the implementation of the S\&T Road Map, and on improved linkage between S\&T communities and GEOSS (including ST-09-02 in the 2009-2011 Work Plan and ID-03 in the 2012-2015 Work Plan). Infrastructure serving and linking S\&T users communities has been developed by these Tasks. 


\section{The Outreach Concept}

Successful outreach to S\&T communities requires demonstration of a benefit for these communities. The S\&T outreach concept for the implementation of the GEO S\&T Road Map takes this fundamental statement as a starting point and provides services to $\mathrm{S} \& \mathrm{~T}$ communities, demonstrates the benefits of GEOSS to S\&T communities, and provides a voice for these communities within GEO. The services are integrated into the GEOSS S\&T Service Suite (G-STSS). Demonstration of the benefits of GEOSS for S\&T communities is based on the GEOSS S\&T Portfolio, which is a component of the G-STSS. The voice of S\&T communities is provided by the GEOSS S\&T Stakeholder Network.

\section{GEOSS Science and Technology Service Suite}

The G-STSS has several outreach components for the demonstration of GEOSS and its value for S\&T communities, and for services supporting S\&T communities in their linkage to, and use of GEOSS. At the core of the G-STSS, the GEOSS S\&T Portfolio includes examples showing GEOSS at work for S\&T communities and provides an avenue for S\&T groups to feature their contribution to GEOSS. A S\&T Meeting Web Portal provides a workspace to coordinate and document GEO and GEOSS participation, side events, and presentations at relevant S\&T meetings. A slide library supports outreach both at S\&T meetings and enables teachers to include information on EOs and their societal benefits in their classes. Workshops of the GEOSS S\&T Stakeholder Network are organized within the G-STSS and the outcomes of the workshops are accessible through the G-STSS. A web-based tool allows the documentation and promotion of research observational infrastructure that should be transitioned to a sustained operation. The G-STSS supports data citation through information on the international discourse on data citation, and the provision of guidelines. The assessment of datasets is supported through the development of a GEO Label. Tools for user feedback on all S\&T aspects related to GEOSS are under development. A database for continuity indicators is also under development, which will inform the development and maintenance of a GEOSS that supports research related to the Grand Challenges of a future sustainable Earth.

\section{The GEOSS S\& T Portfolio}

The GEOSS S\&T Portfolio features a number of compelling examples showing how GEOSS serves S\&T communities in their work. The examples, which have been selected through a rigorous review of proposals

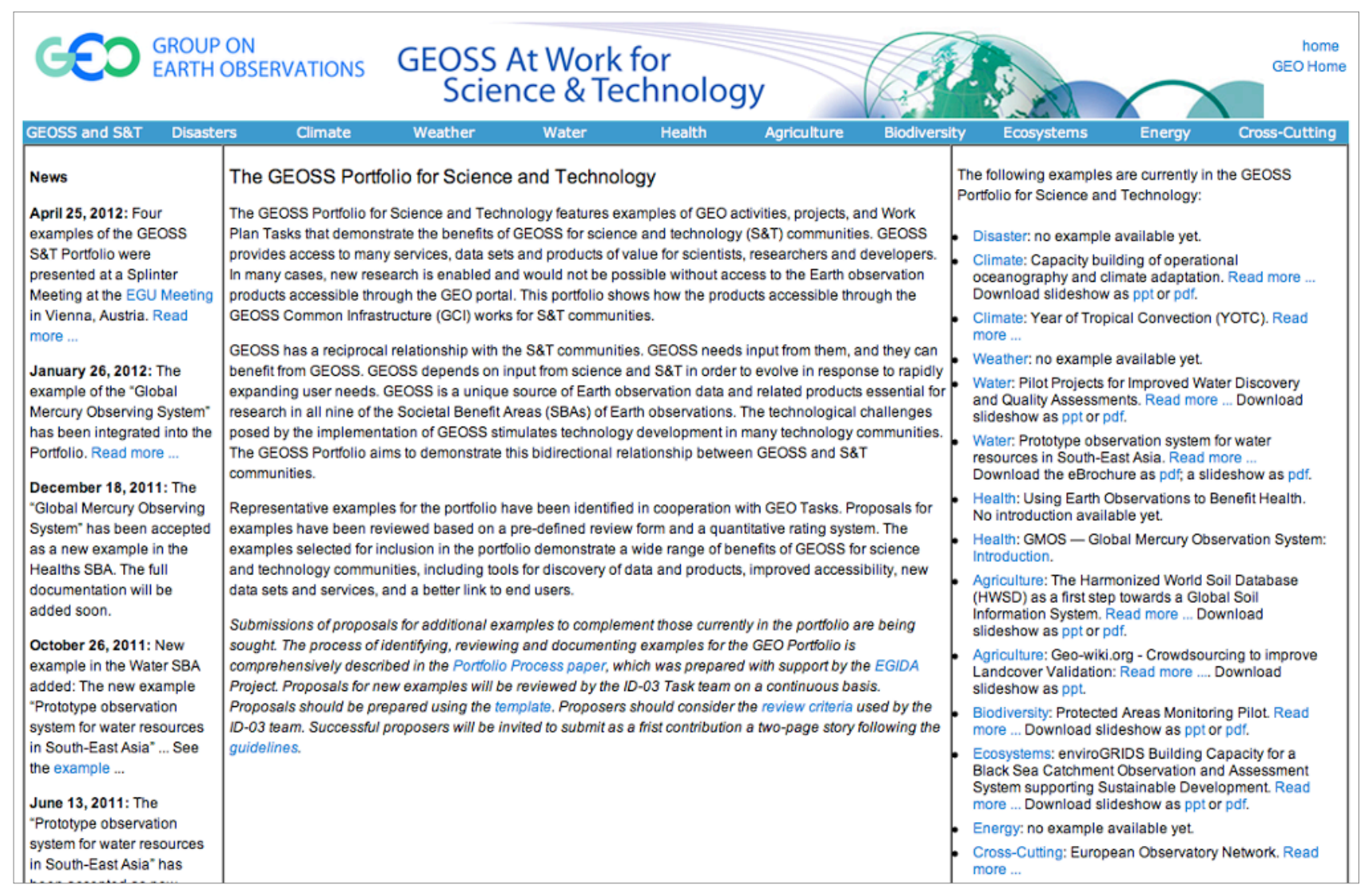

Fig. 1. The home page of the GEOSS S\&T Portfolio, which contains a number of compelling examples that show how GEOSS works for S\&T Communities. 


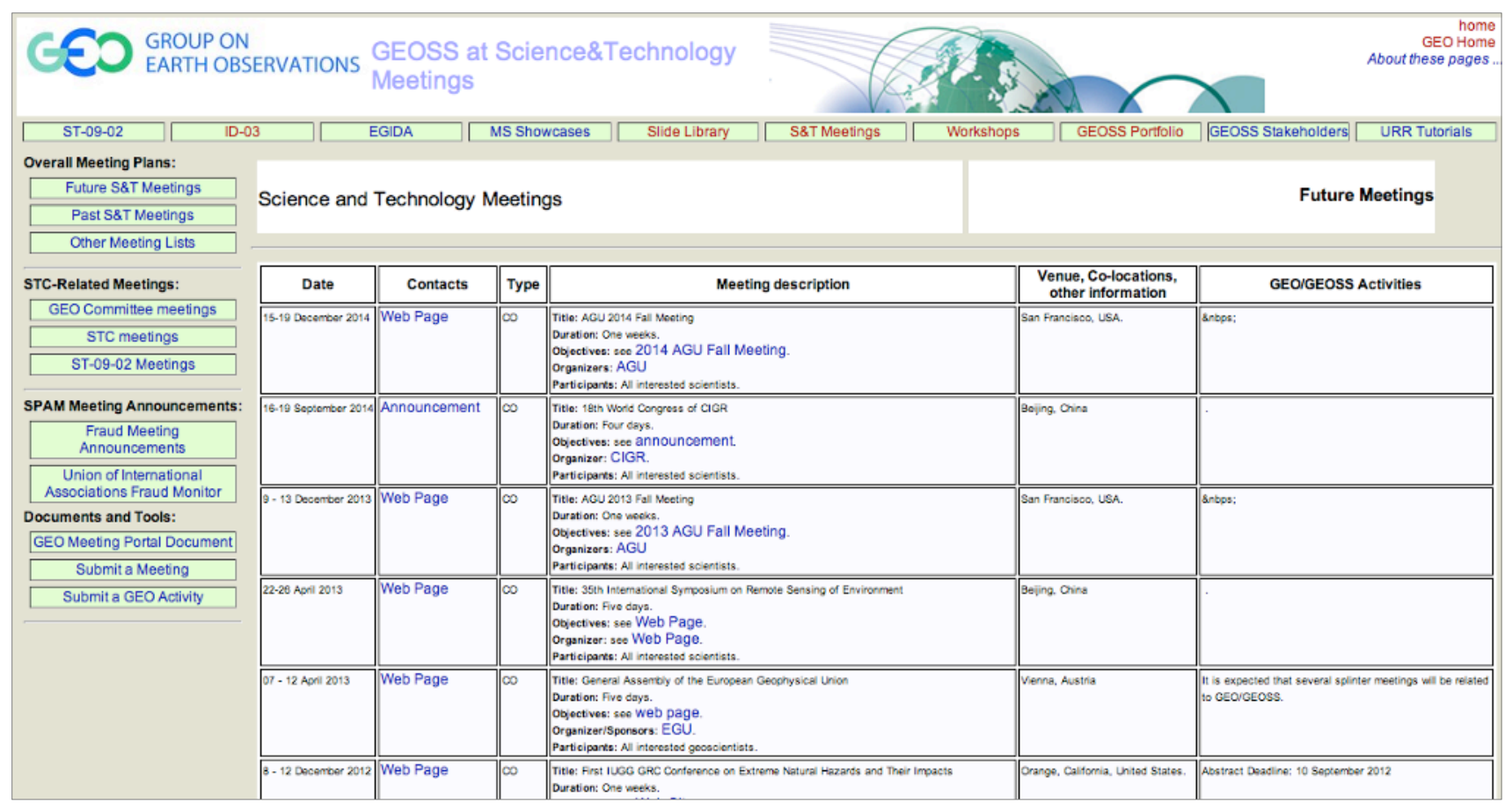

Fig. 2. The Version 0.1 of the GEOSS S\&T Meeting Page. The page provides functionality for the coordination of GEO and GEOSS-related activities as S\&T meetings as well as the documentation of these activities. A fully interactive Version 1.0 is currently under development.

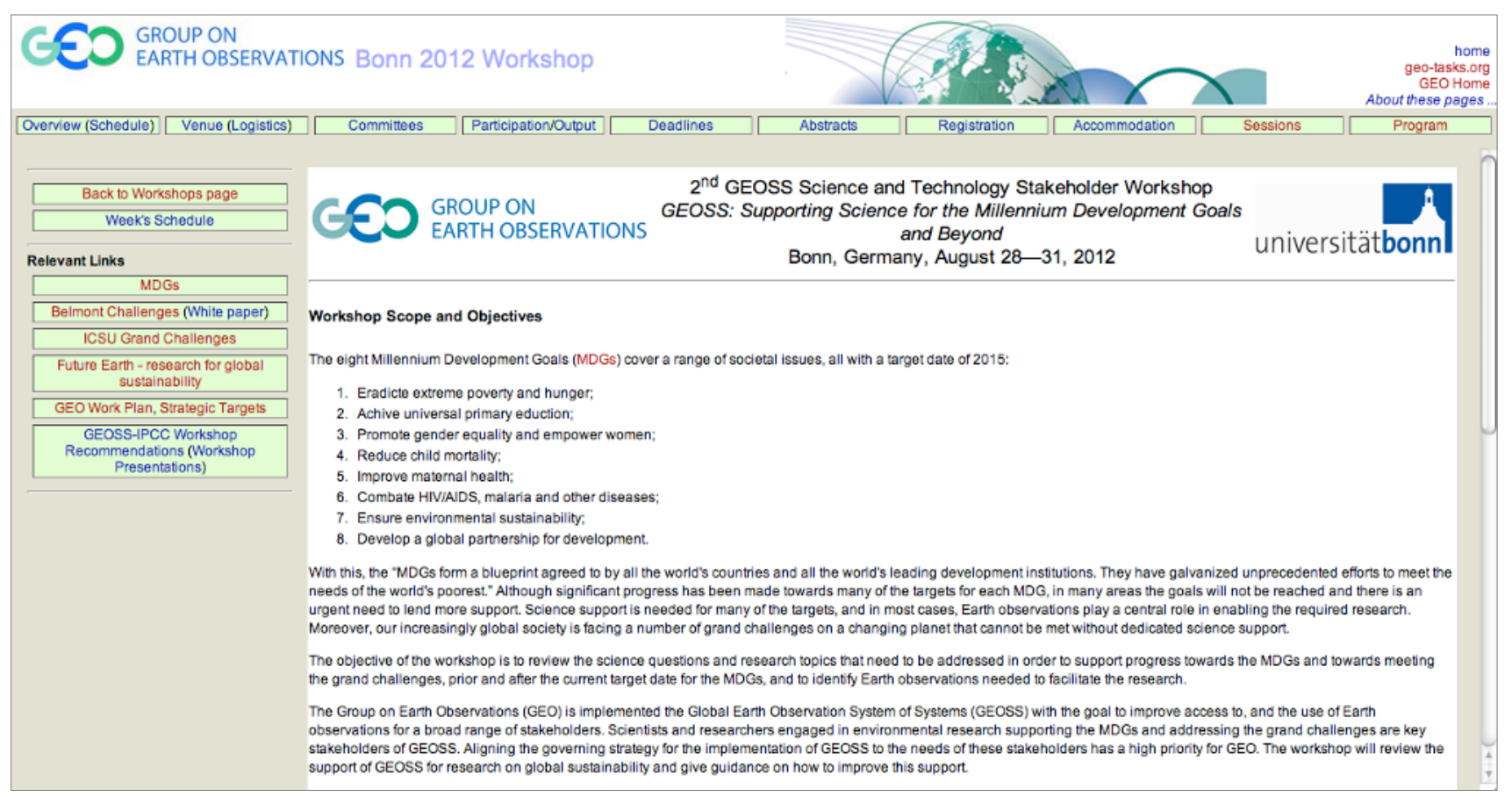

Fig. 3. Home page of the $2^{\text {nd }}$ GEOSS S\&T Stakeholder Workshop available at http://www.geo-tasks.org/workshops /2012_Bonn.

submitted to ST-09-02/ID-03 (Plag, 2012), are accessible through a web page (Fig. 1). The goal is to have at least two examples for each SBA. Currently, not all SBAs are represented through examples, and an effort is being made to solicit additional proposals. The Portfolio is open for submission of additional proposals, and guidelines for the submission are available on the Portfolio web page, currently at http://www.geotasks.org/geoss_portfolio.

For each example, the portfolio provides a short story, emphasizing the particular value of the example. For most examples, slide shows are available, and a few 
examples link to short videos. Once the goal of two examples for each SBA is reached, it is planned to prepare a book and a summary video featuring all examples. The examples are also featured at meetings with outreach components. An example is a Splinter meeting at the 2012 EGU Assembly in Vienna, where four examples were presented by their authors informing the audience about GEO and GEOSS.

\section{The GEOSS S\&T Meeting Portal}

GEO has made significant outreach effort to engage a larger segment of the S\&T communities in GEO, both through specific events and participation in major S\&T meetings. A number of GEO workshops involving S\&T communities have increased awareness of GEO in these communities and beyond. GEO has been present at major science meetings, organized sessions on GEOSS-related topics, convened side events, and facilitated presentations on science applications of GEOSS. To facilitate some level of coordination of these outreach activities, ST-0902 has developed, and ID-03 is maintaining, an interactive web page for the coordination and documentation of outreach at major S\&T meetings (Fig. 2 ). The web page also provides documentation of past GEO activities at science conferences.

The initial version of this S\&T Meeting Portal has limited functionality. A fully interactive version is currently under development. This version will allow the publication of meeting announcements as well as the coordination of GEO and GEOSS-related activities at these meetings. It will be possible to upload presentations and meeting reports, and to publish summary conclusions and recommendation from these activities. Developing this meeting portal into a valuable services for S\&T communities is expected to support the dissemination of information on GEO and GEOSS in these communities.

\section{The GEOSS S\&T Stakeholder Network}

The GEOSS S\&T Stakeholder Network provides an umbrella for all S\&T user and provider communities. The idea of a Stakeholder Network bringing together relevant S\&T communities was developed by the ECfunded EGIDA project. As a first activity, the EGIDA Stakeholder Network organized the $1^{\text {st }}$ Joint Workshop of the EGIDA Stakeholder Network and Advisory Board "Connecting GEOSS and its Stakeholders in Science and Technology," which took place on May 9-11, 2011 in Bonn, Germany (http://www.geo-tasks.org/workshops /2011_Bonn). As an outcome of this workshop, it was decided to extend the EGIDA Stakeholder Network to the GEOSS S\&T Stakeholder Network open to all S\&T providers and users of GEOSS.

The mission of the GEOSS S\&T Stakeholder Network is twofold: to provide a voice for the needs and guidance of S\&T communities to GEO, and to promote the use of GEOSS in these stakeholder communities. Following this mission, the $2^{\text {nd }}$ GEOSS Science and
Technology Stakeholder Workshop, which will take place on August 28-31, 2012 in Bonn, Germany, is titled "GEOSS: Supporting Science for the Millennium Development Goals and Beyond." The objective of this workshop is to review to what extent the Strategic Targets of GEOSS (GEO, 2010) are aligned with the research needs for the Millennium Development Goals (http://www.un.org/millenniumgoals/bkgd.shtml) and the challenges for sustainability identified by the the International Council of Science (ICSU, 2010) and the Belmont Forum (2011) and to provide guidance to the discussion of the post-2015 development of GEOSS.

\section{Conclusion}

The G-STSS aims to link S\&T communities (providers and user) to GEOSS through a service-based approach. The underlying concept assumes that successful outreach to $\mathrm{S} \& \mathrm{~T}$ communities requires demonstration of a benefit for these communities.

\section{Acknowledgements}

The work on several components of the GEOSS S\&T Service Suite and some of the activities of the GEOSS S\&T Stakeholder network were supported by the EGIDA Project co-funded by the European Commission under the 7th Framework Programme (Grant Agreement no: 265124).

\section{References}

Belmont Forum, 2011. The Belmont Challenge: A Global, Environmental Research Mission for Sustainability. See http://www.igfagcr.org/images /documents/belmont_challenge_white_paper.pdf.

GEO, 2010. GEOSS Strategic Targets. GEO Secretariat, Geneva, Switzerland. Avail. at "http://www. earthobservations.org/documents/geo_vi/12_GEOS S Strategic Targets Rev1.pdf"

GEO Science and Technology Committee, 2010: The GEO Science and Technology Road Map. Version 1.1, 11.12.2010. Available at http://www. earthobservations.org/documents/committees/stc/ 201104_16thSTC/stc_roadmap_v1_1_11122010. pdf.

ICSU, 2010. Earth System Science for Global Sustainability: the Grand Challenges. http://www.icsu.org/publications/reports-andreviews/grand-challenges/.

Plag, H.-P. (ed.), 2012. The GEO Process for the Identification, Reviewing, Documentation, and Promotion of Compelling Examples That Show GEOSS at Work for Science and Technology: Compiling a GEOSS Portfolio for Science and Technology. Version 1.4 of January 8, 2012. Available at http://www.geo-tasks.org/geoss portfolio. 